\title{
Terminal Transferase Positive Rat Thymocytes are Resistant to Steroid-induced Apoptosis
}

\author{
Oriana Trubiani*, F.J. Bollum ${ }^{\#}$, and Roberto Di Primio \\ Istituto di Morfologia Umana Normale, Università di Chieti, Via dei Vestini 12, 66100 Chieti, Italy*; \\ Supertechs, 96100 Medical Center Drive, Rockville, MD. 20850, USA \#; Istituto di Morfologia Umana Normale, \\ Università di Ancona, Monte D'Ago, 60131 Ancona, Italy
}

Key words: apoptosis/steroids/terminal deoxynucleotidyl transferase/Bcl-2/thymocytes

\begin{abstract}
Apoptosis is a prominent mechanism of programmed cell death in the immune system. In the thymus apoptosis is responsible for the deletion of autoreactive T-cells during thymic differentiation. The typical features of apoptosis are characterized by nuclear and cytoplasmic morphologic changes, along with cleavage of chromatin at regularly spaced sites. Terminal deoxynucleotidyl transferase (TdT) is a DNA polymerizing enzyme found at an early stage of $T$ and $B$ lymphocyte differentiation, which generates diversity in the DNA sequence of immunoglobulin (Ig) or T cell receptor (TCR). The combined evaluations of thymocyte morphological features, immune phenotype and thymic topography associated to TdT expression allow the recognition of three different thymocyte subpopulations, characterized by small-size, intermediate-size and large-size. The results of this study show that dexamethasone (Dx)-treatment induces cell death via apoptosis involving distinct transformations related to differentiation stages of thymic subpopulations. Intermediate and small-size thymocytes that are TdT-negative or weakly positive at nuclear level are Dx sensitive. In contrast the large-size thymocytes, highly TdT positive, corresponding to the undifferentiated cells, do not show significant morphological modifications and TdT positivity to Dx-treatment. Immunocytochemical analysis shows that Dx-treatment does not affect TdT synthesis but morphological changes, occurring during apoptotic process, are responsive to intracellular movement and intranuclear arrangement of the TdT.
\end{abstract}

The process of negative and positive clonal selection occurring in the thymus leads to death in a plurality of thymocyte subpopulations $(22,28,29,35)$. Apoptosis or programmed cell death occurs at an intermediate stage of differentiation of thymocytes showing a CD4 $4^{+}$, CD8 ${ }^{+}$phenotype and a very low density $\operatorname{TCR}(6,15,17$, $27,34)$. These cells, localized in the deep and in the intermediate cortical areas of the thymus, represent most of the thymic population. Previous works suggested that apoptosis can be artificially induced by irradiation or by glucocorticoids $(2,4,14,30,39,40)$, while physiologically this mechanism can be induced prevalently by TCR or CD3-associated complex activation $(5,32,33)$. The high rate of death within the thymus appears to reflect the molding of the initial TCR repertoire. Mature $T$ cells respond to the antigen in self major histocompatibility (MHC) molecules. During differentiation in the thymus, the TCR repertoire is shaped by both positive and negative events involving MHC molecules (6). Recently the role of steroids in programmed cell death has been shown and since thymic epithelial cells contain

\# To whom correspondence to be addressed. the enzymes required for steroidogenesis, the thymus itself can produce pregnenolone and deoxycorticosterone. These thymic steroids could play a key role in thymocyte survival since it has been shown that the simultaneous presence of TCR and the intranuclear receptors for glucocorticoids prevent, by mutual antagonism, thymocytes death (41). Otherwise, TCR or glucocorticoids in a singular way activated, indece the apoptotic process $(32,33,40)$. The treatment of thymocytes with glucocorticoids provides a convenient way to study cell death in vitro.

The bcl-2 gene was identified at the chromosomal breakpoint of $t(14,18)$ bearing B cell lymphomas (34). bcl-2 is novel among proto-oncogenes that displays an important functional role of blocking programmed cell death in selected hematopoietic cell lines (38). Bcl-2 is detected to the inner mitocondrial membrane and this position is novel for proteins with an oncogenic role. The localization of $\mathrm{Bcl}-2$ suggests that the fundamental metabolic functions of the inner mitochondrial membrane, which include oxidative phosphorylation and electron and metabolite transport, are implicated in the survival mechanism (23). The Bcl-2 protein appears 
then geographically restricted in tissues characterized by apoptotic cell death (24). In the thymus regional distribution suggests that $\mathrm{Bcl}-2$ is differentially regulated during $\mathrm{T}$ cell maturation and involved in the preservation of $\mathrm{T}$ cells.

Terminal deoxynucleotidyl transferase (TdT) is a "creative" DNA polymerase able to generate a somatic diversification between $T$ and $B$ cell clones $(9,11,12)$. In the T-cell compartment the presence of TdT was found related to gene rearrangement coding the T-cell antigen receptor $(7,8,12)$. It has been previously explained $(8,20)$ that TdT positive cells in the rat thymus belong to distinct subsets. Ultrastructural analysis of TdT suggests that the localization of the enzyme is related to thymocyte morphological features and TdT expression corresponds to the maturational stages of $\mathrm{T}$ cells. In this work we have analysed, according to cell-size and TdT expression, the apoptotic process induced by Dx-treatment.

\section{MATERIALS AND METHODS}

Male Sprague-Dawley rats were from Charles River (Milano, Italy). Rabbit polyclonal antibody against 32-KDa calf thymus TdT protein was produced as described (10). Bcl-2 anti-rat antibody was from Santa Cruz Biotechnology, Inc. (Santa Cruz, Ca., USA). Dexamethasone, culture media and all reagent grade materials were from Sigma (St. Louis, Mo., USA). Reagents for electron microscopy were from Polyscience (Warrington, PA., USA).

Thymocytes preparation and dexamethasone treatment. Male Sprague-Dawley rats, 3-5 wks old, were used. The thymus was removed, washed in PBS, and placed in cold RPMI 1640 supplemented with $2 \mathrm{mM}$ L-Glutamine, $100 \mathrm{mM} \mathrm{Na-}$ Pyruvate. The thymus was minced and cells were put in suspension. Cell suspensions were filtered and centrifuged for 4 $\min$ at $400 \mathrm{~g}$, at room temperature. Pellets were resuspended in pre-warmed RPMI 1640 supplemented with 10\% FBS. Cell concentration was adjusted at $1 \times 10^{6}$ cells $/ \mathrm{ml}$. Dexamethasone (Dx) was added as previously reported (31) to the cell suspension at $1 \mu \mathrm{M}$ concentration. Cells were cultured at $37^{\circ} \mathrm{C}$, in a range between 4 to $16 \mathrm{hrs}$ in an atmosphere containing $5 \% \mathrm{CO}_{2}$. Control cultures were done in absence of dexamethasone.

Morphological study. Cell suspensions were fixed with $1.25 \%$ glutaraldehyde in $0.1 \mathrm{M}$ cacodylate buffer, $\mathrm{pH} 7.6$ for 1 hour at $4^{\circ} \mathrm{C}$. After rinsing in the same buffer the fixed cells were postfixed with $1 \% \mathrm{OsO}_{4}$ in cacodylate buffer for 1 hour in a dark cold room. The cells were then washed with buffer and double distilled water and stained overnight using a saturate uranyle acetate aqueous solution. The cell suspensions were then washed, coated with agar, dehydrated with alcohol and toluene, and then embedded in Spurr medium. Thin sections were obtained and observed as described above.

Immunocytochemistry. Immunocytochemistry for TdT lo- calization was carried out as previously described (19-21). Briefly, for electron microscopy, cell suspensions were fixed with $2 \%$ paraformaldehyde in $0.1 \mathrm{M}$ Na-cacodylate buffer, $\mathrm{pH} 7.4$, for $2 \mathrm{hrs}$ and subsequently permeabilized with $0.4 \%$ saponin in Na-cacodylate buffer for $15 \mathrm{~min}$. After several changes of Na-cacodylate buffer containing $0.1 \mathrm{M}$ glycine and $2 \%$ sucrose, fixed and permeabilized cells were incubated overnight with a rabbit anti-calf TdT polyclonal antibody (5 $\mu \mathrm{g}$ $/ \mathrm{ml})$. Cells were then reacted with peroxides-conjugated goat anti-rabbit IgG for 2 hours and incubated, after washing, for $10 \mathrm{~min}$ at room temperature with a substrate for peroxidase detection $(0.05 \mathrm{mg} / \mathrm{ml}$ DAB in $0.05 \mathrm{M}$ Tris- $\mathrm{HCl}$ buffer $\mathrm{pH} \cdot 7.6$ and $0.015 \% \mathrm{H}_{2} \mathrm{O}_{2}$ ). Cell suspensions were then treated with $1 \% \mathrm{OsO}_{4}$ for $1 \mathrm{hr}$, dehydrated and embedded in Spurr medium. Thin sections were stained with lead citrate and observed with a Zeiss 109 electron microscope. In negative controls, the primary or secondary antibodies were omitted.

$D N A$ extraction. At the end of the incubation period, thymocyte cultures were centrifuged for $4 \mathrm{~min}$ at $400 \mathrm{~g}$. The pellet was resuspended in lysis buffer. DNA was extracted with ethanol chloroform/isoamyl alcohol (24:1) and precipitated with 2.5 vol. of absolute ethanol. DNA concentrations were detected by spectrophotometric absorption at $260 \mathrm{~nm}$. Ten $\mu \mathrm{g}$ of DNA/sample was loaded into a $1.8 \%$ agarose gel and electrophoresed. DNA was detected using UV illumination after ethidium bromide staining.

Fluorescence-activated cell sorter (FACS) analysis. Thymocytes were analyzed accordingly to the physical parameters or stained for $30 \mathrm{~min}$ at $4^{\circ} \mathrm{C}$ with anti-rat Bcl-2 mouse monoclonal antibody at 1:100 dilution and revealed using goat antimouse FITC conjugated. Quantitative fluorescence analysis of stained cells was performed on a Coulter Epics Elite flow cytometer (Coulter Inc., USA).

\section{RESULTS}

Agarose gel electrophoresis of DNA (Fig. 1), recovered from Dx-treated thymocytes, shows the DNA pattern characteristic of apoptosis, a chromatin ladder of DNA fragments in multiple, of 180-200 bp. Untreated thymocytes also show many apoptotic bands due to spontaneous apoptotis. Both reacted and untreated thymocytes exhibited similar patterns of DNA fragmentation. Ultrastructural analyses of thymocytes allowed identification of three distinct subpopulations: small, intermediate and large thymocytes, as reported in Fig. 2A. These subpopulations show different sensitivity to Dx-treatment. Four hours later (Fig. 2B), small-size thymocytes appear mostly apoptotic, otherwise intermediated and large-seze cells are normally arranged. At eight hours (Fig. 2C) intermediate thymocytes show features of apoptotic process and at 16 hours (Fig. 2D) extensive degenerative processes are recognizable in small and intermediate apoptotic thymocytes. During Dxtreatment large thymocytes revealed only few modifica- 


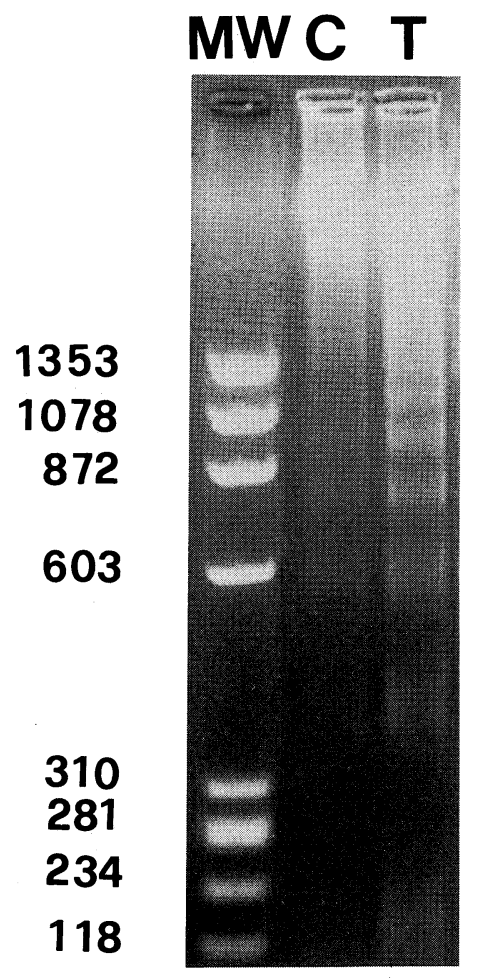

Fig. 1. Agarose gel analysis of DNA from Dx treated (T) and untreated thymocytes $(C)$. The DNA samples were fractionated by electrophoresis in a $1.8 \%$ agarose gel and stained with ethidium bromide. The characteristic ladder-like pattern of DNA banding indicative of apoptotic endogenous nuclease activity is observed prevalently in Dxtreated thymocytes. MW: DNA molecular weight.

tions in the cytoplasmic compartment and the nucleus appeared normally arranged (Fig. 2B, C, D). Dx-treatment producing morphological changes did not affect the TdT synthesis but induces an intracellular redistribution of TdT. In fact, small cells (Fig. 3A) exhibited a smooth surface and their cytoplasm contained only few mitochondria. The nucleus contained predominantly marginated heterochromatin, which often formed a central mass. Small thymocytes were TdT negative both at the nuclear and at the cytoplasmic level (Fig. 3B). After Dx-treatment (Fig. 3C) nuclear changes typical of apoptosis were detected in small thymocytes, lacking major cytoplasmic damage. Nucleolar material was frequently detected at the nuclear periphery and nuclear membrane was sometimes interrupted (Fig. 3C). Dx-treated small thymocytes were TdT negative as untreated cells (Fig. 3D). Intermediate thymocytes (Fig. 4A) were a consistently heterogeneous thymic subpopulation of cells showing a smooth surface. The cytoplasm contained some mitochondria, a Golgi apparatus and isolated profiles of rough endoplasmic reticulum (RER). The nucleus contained a large amount of heterochromatin. Untreated intermediate thymocytes were weakly
TdT positive, predominantly at the cytoplasmic compartment. Sometime it was possible to observe a residual amount of the enzyme present at the nuclear level confined to the euchromatin domains (Fig. 4B). Dxtreated intermediate thymocytes (Fig. 4C) showed apoptotic changes both at the cytoplasmic and at the nuclear levels. The cytoplasm was condensed and contained occasional vacuoles. Apoptotic nuclei displayed peripheral chromatin condensation forming either toroid caps or crescents and the nucleoli show a characteristic pattern of disaggregation. Dx-treated thymocytes (Fig. 4D) remained TdT-positive and the nuclear level reaction was predominantly localized in the residual nuclear matrix. Large thymocytes (Fig. 5A) showed an irregular surface and the abundant cytoplasm contained several mitochondria, ribosomes and RER profiles. The nucleus consisted largely of euchromatin with scanty heterochromatin opposed to the nuclear envelope. One or more nucleoli were also present. These cells appeared to contain a large amount of TdT, diffusely distributed in the cytoplasm and bound to the nuclear interchromatinic region (Fig. 5B). Dx-treated cells (Fig. 5C) displayed a moderate heterochromatin margination. Moreover, typical apoptotic patterns were not detected. Immunocytochemical analyses (Fig. 5D) showed that TdT was localized in the same nuclear euchromatin areas as in the untreated cells. The cytoplasm also displayed a diffuse positivity for TdT. Accordingly to ultrastructural results in flow cytometry, by the analysis of forward light scatter, three different subpopulations were recognizable. Fig. 6A shows that small thymocytes are $15 \pm 10 \%$ of total population, while intermediate and large cells are respectively $65 \pm 10 \%$ and $8 \pm 3 \%$ of total thymocytes. These results are the means of five different experiments and correspond to the date obtained at electron microscope level. Flow cytometry immune fluorescence analysis showed (Fig. 6B) the different expression of Bcl-2 protein connected to size of thymocyte subpopulations. Large-size thymocytes were bright positives, shile intermediate cells constituted a heterogeneous population showing different score of positivity from bright to negative and the small-size cells were prevalently Bcl-2 negative.

\section{DISCUSSION}

Cell death takes two distinct forms, necrosis and apoptosis. Necrosis is considered as a degenerative phenomenon while apoptosis is an active endogenous processes implicated in the regulation of normal, and neoplastic cells $(3,13)$. In the ontogeny of the immune system cell death it occurs by deletion of autoreactive $T$. cell clones during thymic maturation and deletion of $\mathrm{B}$ cells occurs in the germinal center without antigen-coding positive selection of centrocytes $(37,16,17,26)$. The 

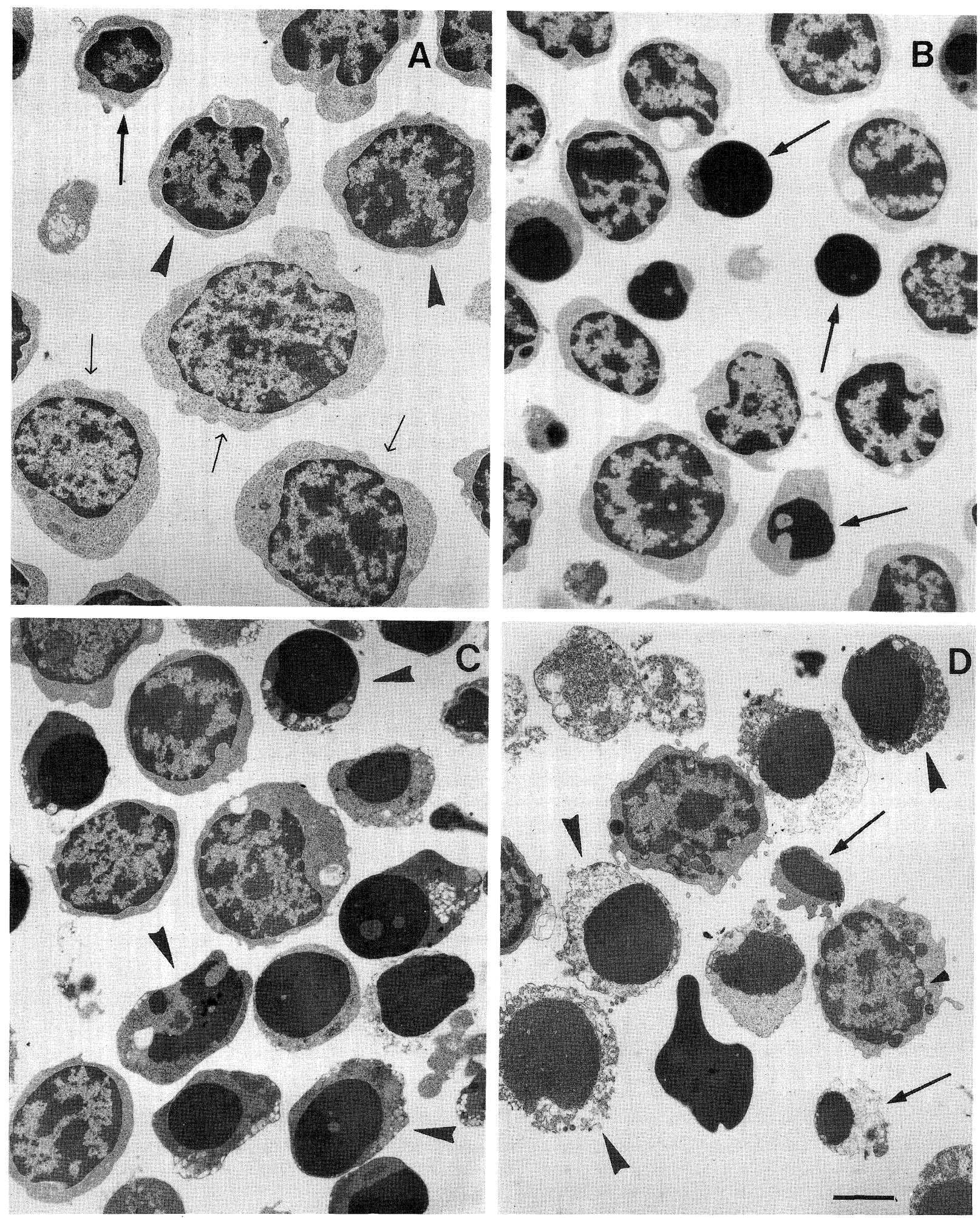

Fig. 2. Morphological analysis of Dx-treated thymocytes. A: Untreated thymocyte sub-populations. Arrows: small thymocytes. Head arrows: intermediate thymocytes. Light arrows: large thymocytes. B: 4 hours of Dx-treatment; it is possible to observe apoptotic features only in smallsize thymocytes (arrows). C: 8 hours of treatment; intermediate cells show typical modification of nuclear compartment (arrowheads). D: 16 hours of treatment; small (arrows) and intermediate thymocytes (arrowheads) show extensive necrotic process. Large cell shows a reduction of cell-size with a light modification of ultrastructure. Bar $5 \mu \mathrm{m}$. 

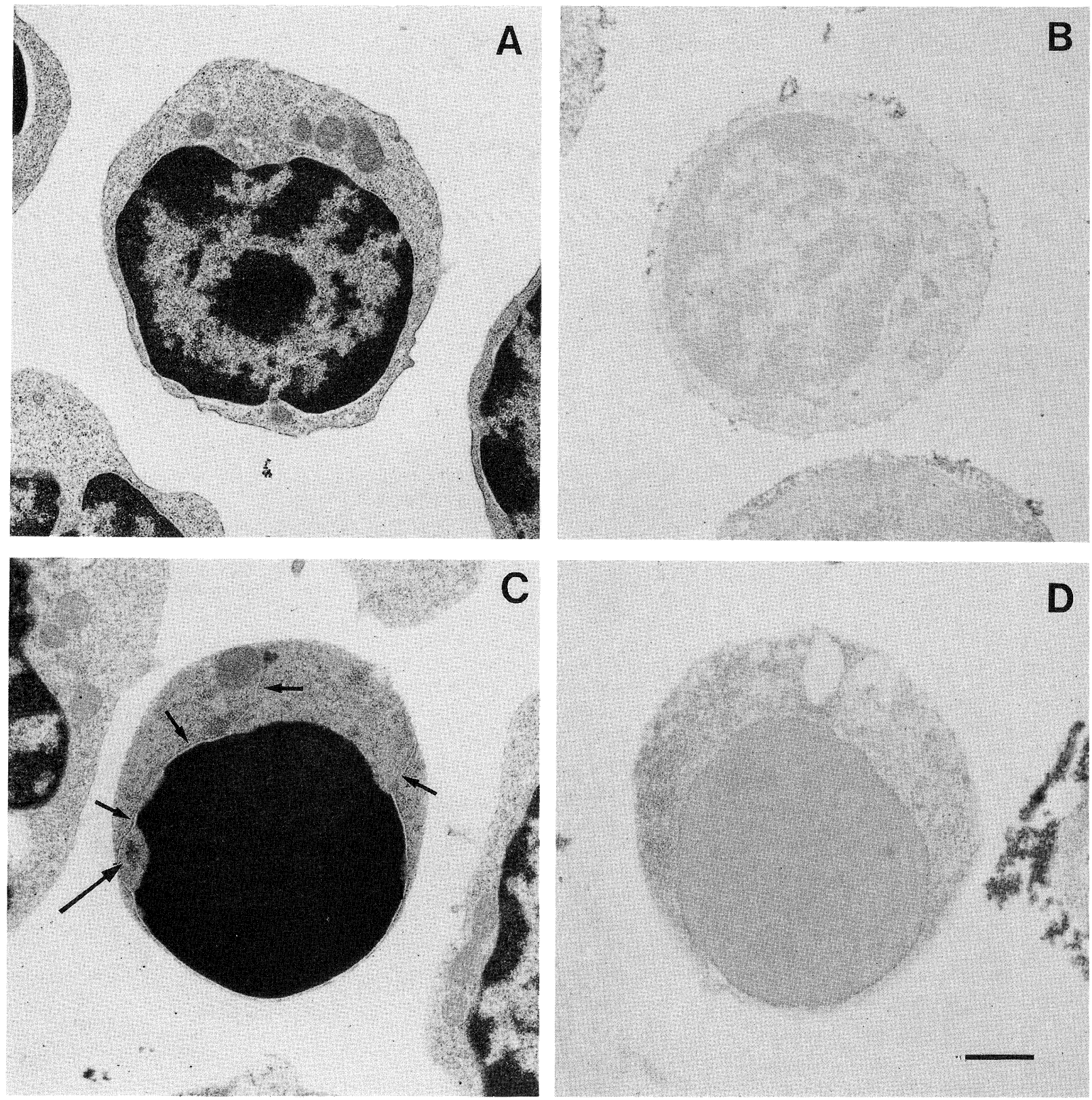

Fig. 3. Transmission electron microscope analysis of glutaraldehyde-osmium tetroxide fixed untreated (A) and treated (C) small-size thymocytes. Immunocytochemical investigation of TdT, performed as described show that untreated (B) and Dx-treated (D) small thymocytes are completely unstained. Nucleolus: arrow. Nuclear membrane: small arrow. Bar $2 \mu \mathrm{m}$.

proto-oncogene bcl-2 has recently been implicated as a component of the molecular processes that decide whether some cell lives or dies (35). In the thymus bcl-2 expression protects immature thymocytes from glucocorticoid, radiation and anti-CD3-induced apoptosis and its presence is related to the differentiation stages of thymocytes $(31,35,38)$. Since terminal transferase has been found in both pre- $\mathrm{T}$ and pre-B lymphocytes and its role consists in producing, at an early stage of differ- entiation, a diversification of the immune-cells by addition of $\mathrm{N}$ nucleotides to the termini segment during $\mathrm{V}$ D-J rearrangement $(1,7,8,18)$. By in situ hybridization, it has been shown that TdT mRNA is confined to the thymic cortex (8), and quantitative analysis using the polymerase chain reaction (PCR) has established that TdT disappears along with up-regulation of the TCR and down-regulation of CD4 or CD8 after positive selection (8). Commitment to the CD4 or CD8 

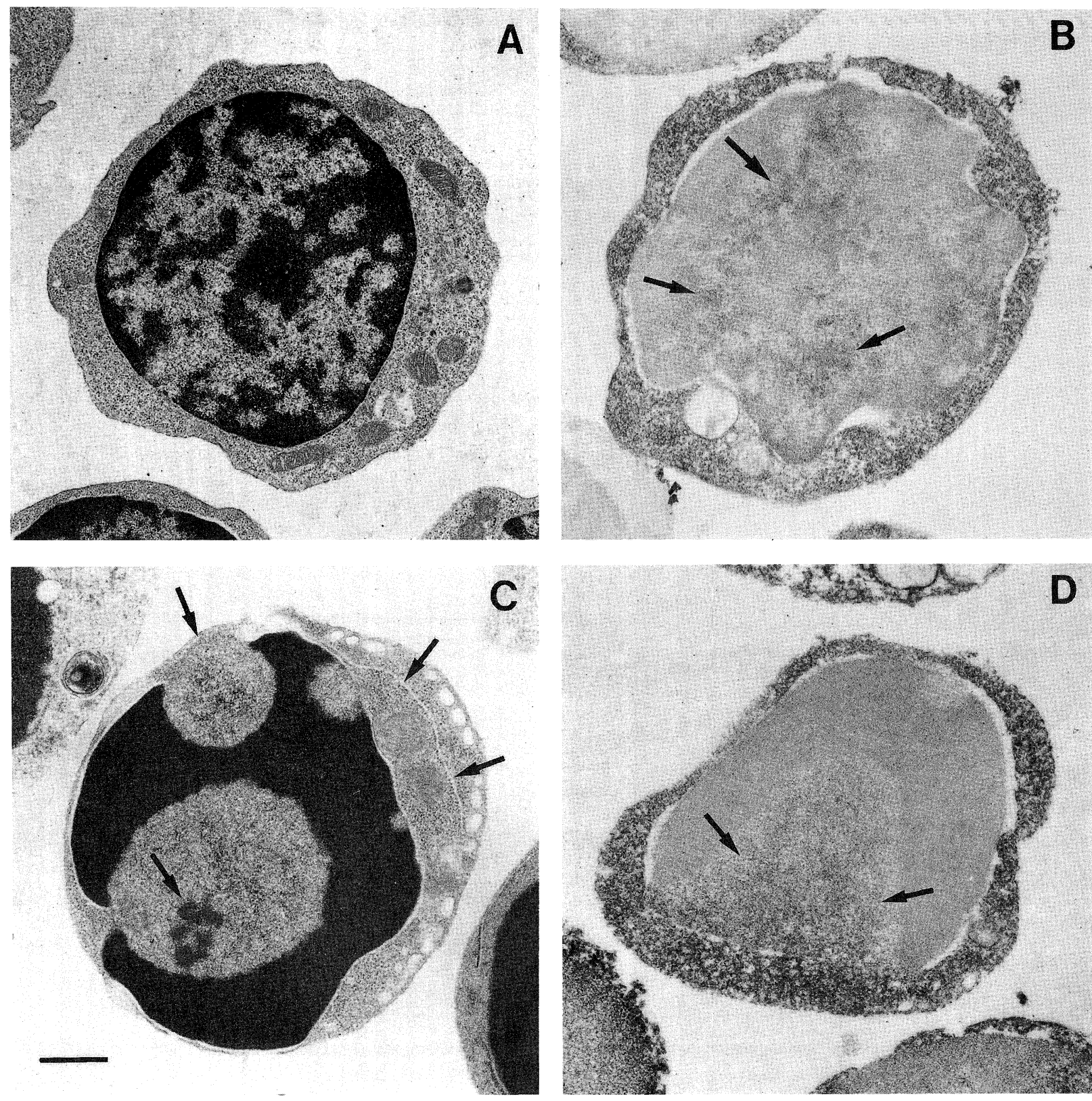

Fig. 4. Analysis of medium size thymocytes. A: ultrastructure of treated cells. B: immunocytochemistry reaction of TdT show a specific staining at the cytoplasmic and nuclear levels (arrows). C: Dx-treated thymocytes display condensed chromatin, nuclear membrane (small arrows) and nucleolus with a characteristic pattern of disintegration (arrows). D: immunocytochemical studies of Dx-treated cells showing dark immunoprecipitate localized in non condensed nuclear chromatin (arrows) and at cytoplasmic level. Bar $2.5 \mu \mathrm{m}$.

lineage was known to occur in the thymus: immature $\mathrm{CD}^{-}{ }^{-} \mathrm{CD}^{-} \mathrm{TCR}^{-}$thymocytes differentiate into $\mathrm{CD}^{+} \mathrm{CD}^{+}{ }^{+} \mathrm{TCR}^{\text {lo }}$ cells, a small percentage of which mature into either $\mathrm{CD}^{+}{ }^{+} \mathrm{CD} 8^{-} \mathrm{TCR}^{\text {hi }}$ or $\mathrm{CD}^{-} \mathrm{CD}^{+}{ }^{+} \mathrm{TCR}^{\text {hi }}$ thymocytes. Entry into these single positive populations required expression of the appropriate positively selecting MHC class I or II molecules on epithelial cells of the thymus $(5,25)$. Therefore, a given cell can then engage MHC molecules on thymic stromal cells with both its TCR and the appropriate coreceptor, along with differentiation; otherwise, it dies. Since apoptosis has been described as a clonal mechanism of deletion of thymocyte subsets expressing inappropriate TCR, in this study we propose that largesize undifferentiated $\mathrm{Bcl}-2$ positive thymocytes expressing TdT at the nuclear level and showing as described 

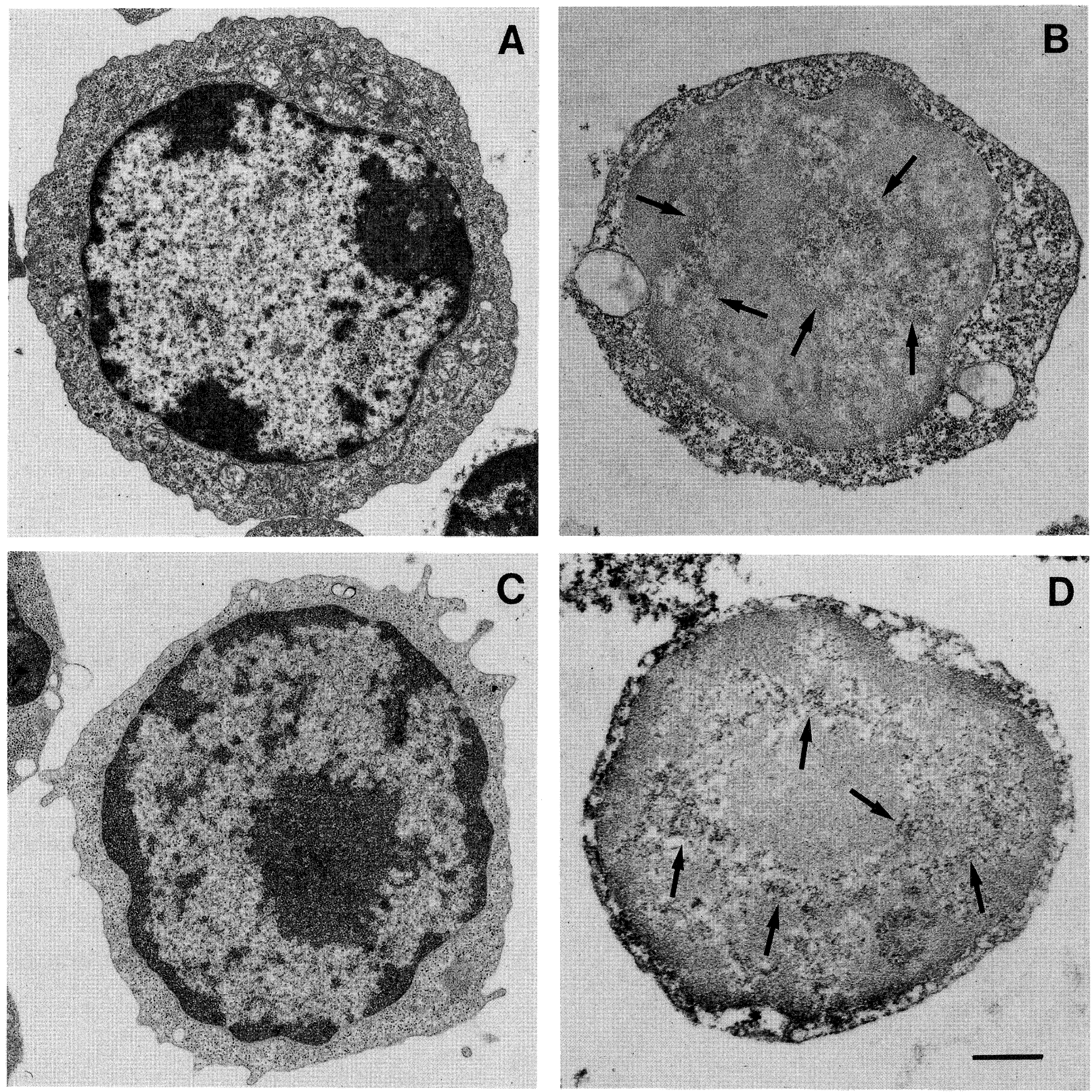

Fig. 5. Analysis of large-size thymocytes. A: morphological features of untreated cells. B: TEM immunocytochemical analysis of TdT shows a large amount of enzyme localized at the nuclear level linked to interchromatinic regions (arrows). C: Dx-treated thymocytes exhibit only a light reduction of cell-size. D: immunocytochemical study of TdT in Dx-treated cells. Immunoprecipitate is localized at the nuclear (arrows) and cytoplasmic levels, as observed in untreated cells. Bar $3 \mu \mathrm{m}$.

$(8,20)$ the phenotype $\mathrm{CD}^{-}{ }^{-} \mathrm{CD}^{-}{ }^{-} \mathrm{TCR}^{-}$are not sensitive to corticosteroid treatments or in detail are not committed to positive or negative selection process. Intermediate and small-size thymocytes, Bcl-2 low positive or negative, which have rearranged the TCR segments contain, at this stage of differentiation, an intrinsic apoptotic program that can be regulated by several specific biochemical events. Dx-treatment, moreover, does not affect the molecular machinery of TdT metabolism, regulated at the early step of thymocyte differentiation, but intracellular movement of the enzyme appears subordinate to the modification of nuclear structure. The experiments reported here suggest that the different response to corticosteroids are related to the stage of thymocyte differentiation and the identification of apoptotic subpopulation will greatly simplify gene expres- 

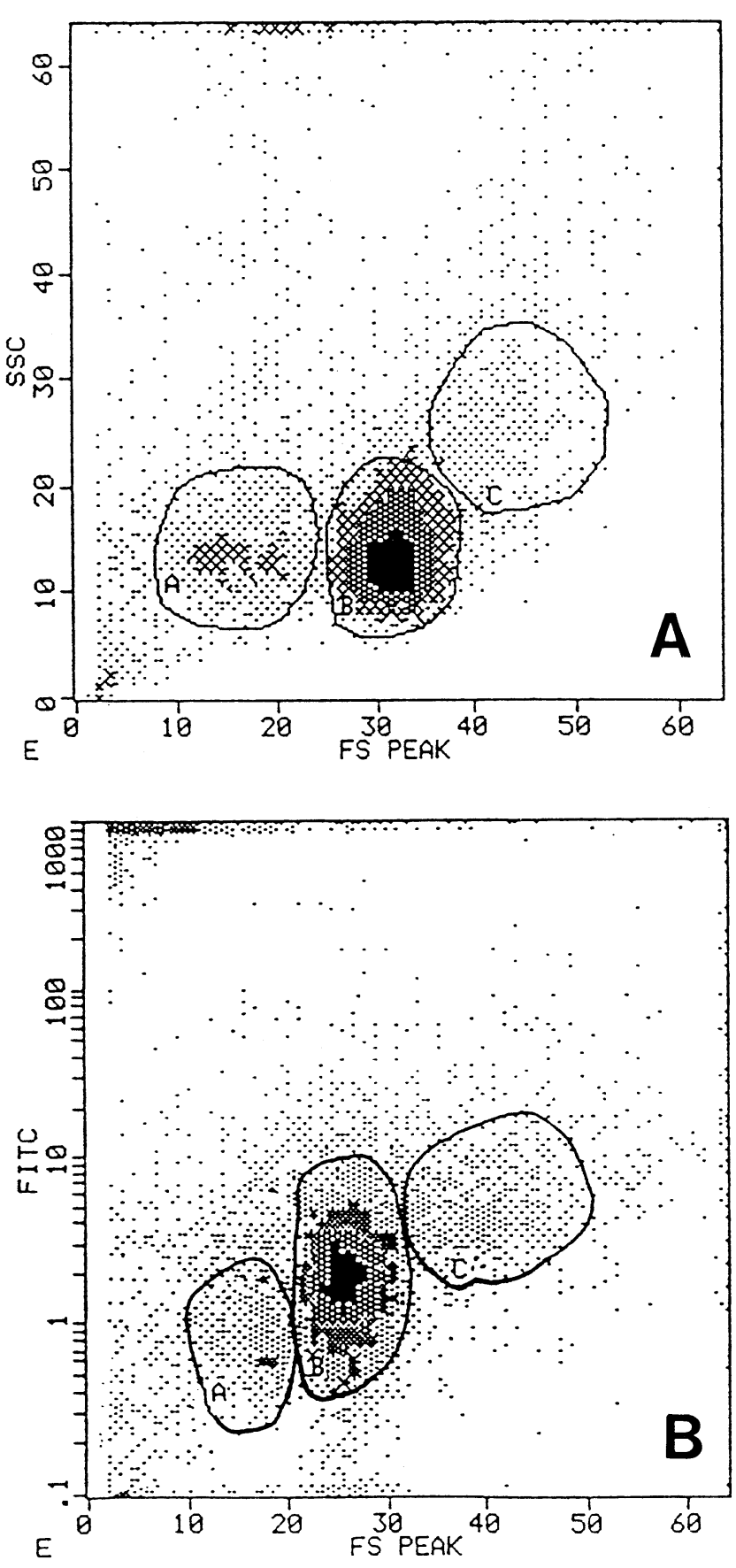

Fig. 6. Flow cytometry analysis of rat thymocytes. Section A: Scatter analysis shows three distinguishable populations: small thymocytes (A), intermediate thymocytes (B) and large-size thymocytes (C). Section B: Flow cytometry alalysis of Bcl-2 protein performed as described in materials and methods section. A: small thymocytes. B: intermediate thymocytes. C: large thymocytes. It is possible to observe the different score of positivity related to the size of the cells. The results showed in section A and B are the same obtained in five different experiments. sion and other mechanistic studies of apoptosis.

Acknowledgments. This study was supported by Italian MURST and CNR grants.

\section{REFERENCES}

1. Alt, F. and Baltimore, D. 1982 . Joining of immunoglobulin chain gene segments: Implications from a chromosome with evidence of three D-JH fusions. Proc. Natl. Acad. Sci. USA, 79: $4118-4122$.

2. Arends, M.J. and Wyllie, A.H. 1991. Apoptosis: mechanism and roles in pathology. Int. Rev. Exp. Pathol., 32: 223254.

3. Ashwell, J.D., Berger, N.A., Cidlowski, J.A., LANe, D.P., and KoRSMEYER, S.J. 1994. Coming to terms with death: apoptosis in cancer and immune development. Immunol. Today, 15: $147-151$.

4. Bansal, N., Houle, A.G., and Melnylovych, G. 1990. Dexamethasone- induced killing of neoplastic cells of lymphoid derivation: lack of early calcium involvement. J. Cell Physiol., 143: 105-109.

5. Berg, L.J., Pullen, A.M., Fazecas de St. Groth, B., Mathis D., Benoist, C., and Davis, M.M. 1989. Antigen/MHC-specific $\mathrm{T}$ cells are preferentially exported from the thymus in the presence of their MHC ligand. Cell, 58: 1035-1046.

6. Blackman, M., Kappler, J., and Marrack, P. 1990. The role of $\mathrm{T}$ cell receptor in positive and negative selection of developing T cells. Science, 248: 1335-1341.

7. Bogue, M., Mossmann, H., Stauffer, U., Benoist, C., and MathIs, D. 1993. The level of N-region diversity in T cell receptors is not pre-ordained in the stem cell. Eur. J. Immunol., 23: $1185-1188$.

8. Bogue, M., Gilfillan, S., Benoist, C., and Mathis, D. 1992. Regulation of N-region diversity in antigen receptors through thymocyte differentiation and thymus ontogeny. Proc. Natl. Acad. Sci. Usa, 89: 11011-11015.

9. Bollum, F.J. 1974. Terminal deoxynucleotidyl Transferase. In Boyer, R.D. ed., The Enzymes. New York: Academic Press, 10: $145-151$.

10. Bollum, F.J. 1975. Antibody to Terminal deoxynucleotidyl Transferase. Proc. Nat. Acad. Sci. USA, 72: 4119-4122.

11. Bollum, F.J. 1963. Progress in nucleic acid research. Vol.I, Academic Press, New York, pp.1-66.

12. Cayre, Y., De SostoA, A., and Silverstone, A.E. 1981. Isolation of subset of thymocytes inducible for Terminal Transferase biosynthesis. J. Immunol., 126: 553-556.

13. Cohen, J.J. and Duke, R.C. 1992. Apoptosis and programmed cell death in immunity. Annu. Rev. Immunol., 10: 267293.

14. Cohen, J.J. and Duke, R.C. 1984. Glucocorticoid activation of a calcium-dependent endonuclease in thymocyte nuclei leads to cell death. J. Immunol., 132: 38-42.

15. Cohen, G.M., Sun, X.-M., Snowden, R.T., Ormerod, M.G., and Dinsdale, D. 1993. Identification of a transitional preapoptotic population of thymocytes. J. Immunol., 151: 566574.

16. Crompton, T., Ohashi, P., Schneider, S.D., Pircher, H., and MaCDonald, H. 1991. A cortisone sensitive CD3 $3^{\text {low }}$ subset of $\mathrm{CD}^{+}{ }^{+} \mathrm{CD} 8^{-}$thymocytes represents an intermediate stage in intrathymic repertoire selection. Int. Immunol., 4: 153-161.

17. Dent, A.L., Matis, L.A., Bluestone, J.A., and Hedrick, 
S.M. 1993. Evidence for programmed cell death of self-reactive T cell receptor-positive thymocytes. Eur. J. Immunol., 23: 2482-2487.

18. Desiderio, S.V., Yacopoulos, G.D., Paskind, M., Thomas, E., Boss, M.A., Landau, N., Alt, F.W., and Baltimore, D. 1984. Insertion of $\mathrm{N}$ region into heavy-chain genes is correlated with expression of Terminal deoxynucleotydyl Transferase in B cells. Nature, 311: 752-755.

19. Di Primio, R. and Bollum, F.J. 1987. Immunoenzymatic method for detection of Terminal deoxynucleotidyl Transferase by light and electron microscopy. Hemat. Pathol., 3: 173-181.

20. Di Primio, R., Trubiani, O., and Bollum, F.J. 1992. Ultrastructural localization of Terminal deoxynucleotydyl Transferase (TdT) in rat thymocytes. Thymus, 19: 183-190.

21. Di Primio, R., Trubiani, O., and Bollum, F.J. 1992. Intracellular localization of Terminal Transferase during the cell cycle. Exp. Cell Res., 202: 405-411.

22. EzINe, S. and Ceredig, R. 1994. Haemopoiesis and early Tcell differentiation. Immunol. Today, 15: 151-154.

23. Hockenbery, D., Hunez, G., Milliman, C., Schreiber, R.D., and KorsmeYer, S.J. 1990. Bcl-2 is an inner mitochondrial membrane protein that blocks programmed cell death. Nature, 348: 334-336.

24. Hockenbery, D., Zutter, D.M., Hickey, W., Nahm, M., and KORSMEYER, S.J. 1991. Bcl-2 protein is topographically restricted in tissue characterized by apoptotic cell death. Proc. Natl. Acad. Sci. USA, 88: 6961-6965.

25. Kisielow, P., Teh, H.S., Bluthmann, H., and von Boehmer, H. 1988. Positive selection of antigen-specific $\mathrm{T}$ cells in thymus by restricting MHC molecules. Nature, 335: 730-733.

26. Liu, Y.J., Joshua, D.F.E., Williams, G.T., Sмith, C.A., Gordon, J., and MacLennan, I.C.M. 1989. Mechanism of antigen-driven selection in germinal centres. Nature, 342: 929 931.

27. Murphy, K.M., Heimberger, A.B., and LoH, D.Y. 1990. Induction by antigen of intrathymic apoptosis of $\mathrm{CD}^{+}{ }^{+} \mathrm{CD} 8{ }^{+} \mathrm{TCR}^{\text {low }}$ thymocytes in vivo. Science, 250: 1720 1723.

28. Reinherz, E.L. and Schlossman, S.F. 1980. The differentiation and fuction of human T lymphocytes. Cell, 19: 821-827.

29. Rothenberg, E.M. 1992. The development of fuctionally responsive T cells. Adv. Immunol., 51: 185-214.

30. Sellins, K.S. and Cohen, J.J. 1987. Gene induction by $\gamma$-irradiation leads to DNA fragmentation lymphocytes. J. Immunol., 139: 3199-3206.
31. Sentman, C.L., Shutter, J.R., Hockenbery, D., Kanagawa, O., and KorSMEYeR, S.J. 1991. Bcl-2 inhibits multiple forms of apoptosis but not negative selection in thymocytes. Cell, 67: 879-888.

32. Shi, Y.F., Bissonnette, R.P., Parfrey, N., Szalay, M., Kubo, R.T., and GREEN, D.R. 1991. In vivo administration of monoclonal antibodies to the CD3 $\mathrm{T}$ cell receptor complex induces cell death (apoptosis) in immature thymocytes. J. Immunol., 146: 3340-3346.

33. Smith, C.A., Williams, G.T., Kingston, R., Jenkinson, E.J., and OwEN, J.J.T. 1989. Antibodies to CD3/T-cell receptor complex induce death by apoptosis in immature $\mathrm{T}$ cells in thymic cultures. Nature, 337: 181-184.

34. Snodgrass, H.R., Kisielov, P., Kiefer, M., Steinmetz, M., and VON BOEHMER, H. 1985. Ontogeny of the T-cell antigen receptors within the thymus. Nature, 313: 592-595.

35. Strasser, A., Harris, A.W., and Cory, S. 1991 . Bcl-2 transgene inhibits $\mathrm{T}$ cell death and perturbs thymic self-censorship. Cell, 67: 889-899.

36. Tsujimoto, J., Gorham, J., Comman, J., Jaffe, E. and Croce, C.M. 1985. The $t(14 ; 18)$ chromosome translocations involved in B cell neoplasm results from mistakes in VDJ joining. Science, 229: 1390-1393.

37. Turka, L.A., Linsley P.S., Paine III, R., Schieven, G.R., Thompson, C.B., and LedBetTer, J.A. 1991. Signal transduction via $\mathrm{CD} 4, \mathrm{CD} 8$, and $\mathrm{CD} 28$ in mature and immature thymocytes: implications for thymic selection. J. Immunol., 146: 1428-1436.

38. Vaux, D.L., Cory, S., and Adams, J.M. 1988. Bcl-2 gene promotes haemopoietic cell survival and cooperates with c-myc to immortalize pre-B cells. Nature, 335: 440-442.

39. Wyllie, A.H. 1980. Glucocorticoid-induced thymocyte apoptosis is associated with endogenous endonuclease activation. $\mathrm{Na}$ ture, 284: 555-556.

40. Yamada, T. and Ohyama, H. 1988. Radiation-induced interphase death of rat thymocytes in internally programmed (apoptosis). Int. J. Radiat. Biol. Relat. Stu. Phys. Chem. Med., 53: $65-75$.

41. Zacharchuk, C.M., Mercep, M., Chakraborti, P.K., SiMONS, S.S. JR., and Ashwell, J.D.. 1990. Programmed T lymphocyte death. Cell activation and steroid-induced pathways are mutually antagonistic. J. Immunol., 145: 4037-4045.

(Received for publication, June 30, 1995 and revised form, September 29, 1995) 